\title{
Preparation of ceramic nanofibers of iron vanadate using electrospinning method
}

\author{
YASAMAN KHAKSARFARD ${ }^{1}$, HAKIMEH ZIYADI $^{2, *}$, AKBAR HEYDARI $^{3}$ \\ ${ }^{1}$ Active Pharmaceutical Ingredients Research Center, Tehran Medical Sciences, Islamic Azad University, Tehran, Iran \\ ${ }^{2}$ Department of Organic Chemistry, Faculty of Pharmaceutical Chemistry, Tehran Medical Sciences, Islamic Azad University, \\ Tehran, Iran \\ ${ }^{3}$ Chemistry Department, Tarbiat Modares University, Tehran, Iran
}

\begin{abstract}
Because of special characteristics of vanadate compound, such as its sustainability, magneticity, high selectivity in reactions and catalytic character, this study aimed to preparation and analyzing novel ceramic iron vanadate $\left(\mathrm{FeVO}_{4}\right)$ nanofibers. The ceramic nanofibers of iron vanadate were made by the combination of sol-gel and electrospinning methods. First, polyvinyl alcohol (PVA), as a matrix polymer, was mixed separately with ammonium metavanadate $\left(\mathrm{NH}_{4} \mathrm{VO}_{3}\right)$ and iron (III) nitrate $\left(\mathrm{Fe}\left(\mathrm{NO}_{3}\right)_{3}\right)$. As a result, the spinnable polymeric gel was obtained from the controlled mixture of these two precursors of ceramic material. Electrospinning of PVA/iron (III) nitrate/ammonium vanadate solution was done using an Electroris setup that enabled preparation of polymeric template nanofiber. Finally, iron vanadate nanofiber was obtained by calcination of polymer nanofiber at controlled temperature. The products were characterized with scanning electron microscope (SEM), energy dispersive X-ray spectroscope (EDX), X-ray diffraction (XRD), Fourier transform infrared spectroscopy (FT-IR), vibrating sample magnetometer (VSM) and Brunauer-Emmett-Teller (BET) surface area analysis.
\end{abstract}

Keywords: electrospinning; nanofiber; ceramics; iron vanadate

\section{Introduction}

Nanofibers are a type of microscopic onedimensional nanomaterials that have a large surface area because of their very small diameter, yet very large length [1]. Regarding the importance of nanotechnology, researchers are very interested in studying the unique properties of nanoscale materials, such as nanofibers. Thus, the production of fine novel fibers with unique properties has always been of great interest to researchers. Over the past two decades, several methods have been proposed for the production of these fibers and some have been developed industrially [2].

Electrospinning is a widely used technique to manufacture nanofibers. In this method, electrical energy causes spinning of polymers from a nozzle to a drum in the form of fibers with a diameter in the range of nanometers to micrometers [3, 4].

*E-mail: behnazziyadi@yahoo.com
Studies in this field are still in progress due to simplicity, controllability, industrialization capability, and variety of manufactured products. In the past few years, the production of nanofibers has made remarkable progress. For example, the production of high-performance carbon nanofibers, twocomponent nanofibers, hollow nanofibers, modified nanofibers, intelligent nanofibers, core-shell nanofibers, and ceramic nanofibers has been done successfully [5].

Electrospinning method is one of the most practical methods for producing mineral ceramic nanofibers. In this method, first, an electrospinnable solution is prepared with the help of some processes such as sol-gel or simple mixing of a polymer with precursor or metal salts. Then, the electrospinning of solution containing mineral precursor to fabricate nanofibers is followed by calcination at high temperature $[6,7]$. The ceramic nanofibers produced by this method show unparalleled characteristics and properties, 
such as one-dimensional morphology, high length, porosity, high magneticity, and a high surface area [8]. Other worthy features include freestanding, easy handling, and membrane-like formulation. Ceramic nanofibers have many biomechanical, pharmaceuticals, technological, and environmental applications $[9,10]$.

Metal orthovanadates (MVO4) are an interesting class of ceramic compounds with numerous applications in various fields such as solar cells, gas sensors, cathodes in lithium batteries, and more importantly as catalysts [11-14]. Iron vanadate has different distinguishing characteristics such as stability, magneticity, and high selectivity in reactions. Therefore, it is used in various applications such as photocatalysis of organic pollutants [15], gas sensors [16], electrodes [17], and catalysts [18]. There are different methods for the preparation of iron vanadate such as hydrothermal, co-precipitation, chemical, and solid-state methods [19-22]. All the above-mentioned processes have their own problems: complexity of the path, long reaction time, and difficulty in controlling morphology of the structures. In one study, Nithya et al. [23] used a wet chemical method to synthesize iron vanadate. In this process, the reaction of iron (III) nitrate and ammonium metavanadate solution at $75{ }^{\circ} \mathrm{C}$ initially led to the precipitation of iron (III) monohydrated vanadate $\left(\mathrm{FeVO}_{4} \cdot \mathrm{H}_{2} \mathrm{O}\right)$ and then calcination at $550{ }^{\circ} \mathrm{C}$ produced iron vanadate without water. Generally, iron vanadate produced by the above methods has nanoparticles, nanobars, or nanocubes morphology [24-26]. To the best of the authors' knowledge, nanofibers of iron vanadate have not been prepared until now. Nevertheless, the synthesis of ammonium vanadate nanofibers, zinc vanadate nanofibers, vanadium oxide nanofibers, and copper vanadate nanofibers have been studied [27-30].

In the current study, an innovative and novel method based on the electrospinning has been introduced for the production of ceramic nanofibers of iron vanadate. The viscosity and conductivity of the prepared solution were also measured. The ceramic product was characterized using XRD, SEM, FT-IR, VSM and BET analyses.

\section{Experimental}

\subsection{Materials and apparatus}

All chemicals were purchased from Merck Chemicals Co. The electrospinning process was carried out using Electroris (FNM Ltd.) as an electrospinner device. This device has controllable components such as high voltage supply, syringe pump, drum, and nozzle. Calcination was carried out using Exciton furnace (Exciton Co. Ltd., Iran) that provided a heating rate control up to $1800{ }^{\circ} \mathrm{C}$.

\subsection{Characterization}

The obtained products were characterized using SEM, EDX, XRD, FT-IR, VSM and BET analyses. SEM images were taken on gold coated samples using SEM (Philips XL 30 and S-4160) equipped with energy dispersive $\mathrm{X}$-ray spectroscopy (EDX). Powder XRD spectrum was recorded at room temperature with a Philips X'Pert XL 30 diffractometer using $\mathrm{CuK} \alpha$ radiation $(\lambda=1.54056 \AA)$ in Bragg-Brentano geometry ( $\theta$ to $2 \theta$ ). FT-IR spectra were measured in the region of $400 \mathrm{~cm}^{-1}$ to $4000 \mathrm{~cm}^{-1}$ with Shimadzu $8400 \mathrm{~s}$, Japan and spectroscopic grade $\mathrm{KBr}$. Magnetic properties of the catalyst were studied by using vibrating sample magnetometer/alternating gradient force magnetometer (VSM/AGFM, MDK Co., Iran). BrunauerEmmett-Teller (BET) surface area analysis and Barrett-Joyner-Halenda (BJH) pore size and volume analysis of nanofibers was performed by the Micromeritics TriStar II Plus model device. Conductometer of AZ instrument Crop, Taiwan was used for conductivity measurement. As for viscosity measurement, Brookfield, USA, viscometer was applied.

\subsection{Preparation of polymer nanofibers and ceramic nanofibers}

First, $10 \% \mathrm{w} / \mathrm{w}$ of the polymeric solution in water was prepared. For this purpose, $1 \mathrm{~g}$ of polyvinyl alcohol (PVA) $(72,000 \mathrm{~g} / \mathrm{mol})$ was added to $10 \mathrm{~mL}$ deionized water at $50{ }^{\circ} \mathrm{C}$ with stirring for $3 \mathrm{~h}$. Then, $0.12 \mathrm{~mol}(0.014 \mathrm{~g})$ ammonium monovanadate was mixed in $5 \mathrm{~mL}$ PVA solution for $1 \mathrm{~h}$ at room temperature. Other solutions containing the second 
precursor were prepared using the same method by mixing $5 \mathrm{~mL}$ PVA with $0.12 \mathrm{mmol}$ iron nitrate $(0.05 \mathrm{~g})$. Two polymer solutions were mixed drop by drop to produce the homogenous polymeric solution in the presence of $4 \% \mathrm{w} / \mathrm{w}$ of Tween 80 as a surfactant. The obtained solution was loaded into a plastic syringe with the inner diameter of pinhead of $0.80 \mathrm{~mm}$. The syringe was connected to the Electroris as an electrospinner device. Aluminum foil around the drum served as nanofibers collector. The electrospinning conditions in this experiment were as follows: $20 \mathrm{kV}$ voltage, $1 \mathrm{~mL} / \mathrm{h}$ flow rate and $12 \mathrm{~cm}$ distance between the capillary and the collector. Next, the electrospun nanofibers were peeled off from the foil and inserted in a vacuum oven for $1 \mathrm{~h}$ at room temperature in order to remove the solvent residuals. Finally, the polymeric nanofibers were calcined for $3 \mathrm{~h}$ in air at $500{ }^{\circ} \mathrm{C}$, $550{ }^{\circ} \mathrm{C}, 600{ }^{\circ} \mathrm{C}$ and $700{ }^{\circ} \mathrm{C}$ at different heating rates of $20^{\circ} \mathrm{C} / \mathrm{min}$ and $1{ }^{\circ} \mathrm{C} / \mathrm{min}$. The complete elimination of organics led to the fabrication of the ceramic nanofibers.

\section{Results and discussion}

It is generally accepted that there are three important steps in ceramic nanofiber production: (i) solution preparation, (ii) electrospining, and (iii) calcination. The solution for electrospining should be a polymer or sol containing metal ion precursor. For synthesis of iron vanadate, iron (III) nitrate and ammonium monovanadate were used as precursors of iron (III) and vanadium, respectively. According to the literature, mixing of these compound solutions at a specific concentration, results in the formation of gels. Then, in controlled heating conditions, the corresponding nanoparticles can be produced [23]. In order to control the viscosity and electrospinning process of the solution, PVA was used as a polymer to be mixed with metal ions. PVA is a water-soluble, biodegradable, inexpensive and non-toxic synthetic polymer. This polymer is a good candidate for a matrix to immobilize metal ions in ceramic nanofibers production because its organic structure is completely eliminated during heating at high temperature by conversion to carbon dioxide and water. For these purposes, first,
PVA solution was mixed with iron (III) nitrate and ammonium monovanadate, separately. Then, these two solutions were mixed in presence of Tween 80 as a surfactant drop by drop. The viscosity of prepared PVA/iron (III) nitrate/ammonium monovanadate solution, measured by viscometer, was $3.579 \mathrm{~Pa} \cdot \mathrm{s}$ at $20 \mathrm{~s}^{-1}$ shear rate and $0.0076 \mathrm{~N} / \mathrm{cm}^{2}$ shear stress that was sufficient for formation of Taylor cone [31]. The electrical conductivity, measured by conductometer, was $4.17 \mathrm{mS} / \mathrm{m}$. As the high-quality deionized water has a conductivity of about $5.5 \mu \mathrm{S} / \mathrm{m}$ at $25{ }^{\circ} \mathrm{C}$, thus, the electrospining solution conductivity was one hundred times higher than that of the deionized water. Good viscosity with sufficient entanglement and high conductivity is necessary for fiber formation during electrospinning [32]. The prepared solution was loaded into a syringe, which was connected to Electroris device. After electrospinning, the morphology of polymeric composite nanofibers was characterized using SEM (Fig. 1a). This image shows the formation of narrow, uniform polymeric composite nanofibers with smooth surface morphology. It also shows that the electrospinning of this solution was successful without formation of nodes, sediment, or heterogeneities. The obtained histograms (Fig. 1b) confirm the narrow diameter distribution for 18 observed nanofibers. The average diameter of the composite PVA/iron (III) nitrate/ammonium monovanadate nanofibers is $134 \mathrm{~nm}$.

Then, the polymer nanofibers were calcined at different temperatures to produce ceramic nanofibers by removing organic and polymer matrix. Fig. 2a shows the SEM image of the nanofibers after calcination at $500{ }^{\circ} \mathrm{C}$ at $20{ }^{\circ} \mathrm{C} / \mathrm{min}$ rate of temperature rise. It can be seen that the nanofibers are crumpled and PVA has not been removed completely. The reason for these wrinkles could be the high rate of temperature rise. Therefore, in the next step, the experiment was repeated at $550{ }^{\circ} \mathrm{C}$ with $1{ }^{\circ} \mathrm{C} / \mathrm{min}$ rate of temperature rise. As shown in Fig. $2 b$, the ceramic nanofibers have formed successfully. The nanofibers exhibit a few raptures with rough surface. Fig. $2 c$ and Fig. $2 d$ show the fibers after thermal treatment at higher temperatures. The nanofibers calcined at $600{ }^{\circ} \mathrm{C}$ have irregular shapes and many ruptures in the axial 

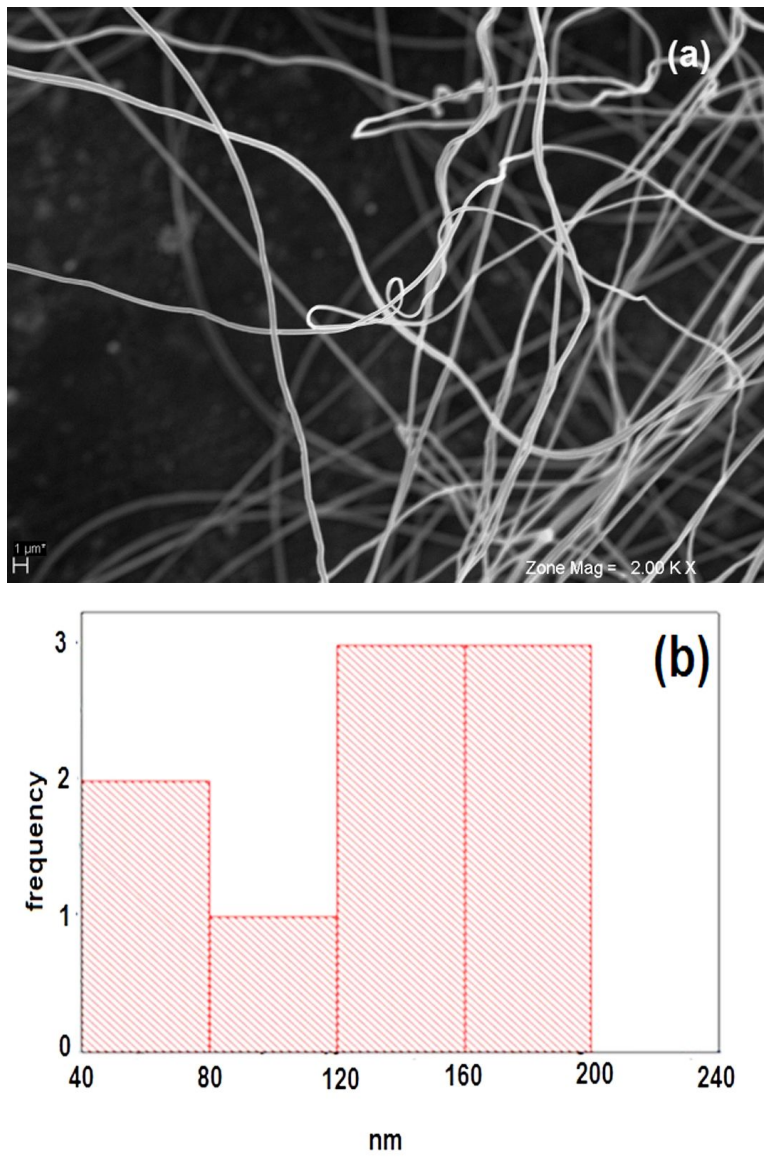

Fig. 1. (a) SEM image (b) fiber diameter distribution of electrospun PVA/iron (III) nitrate/ammonium monovanadate nanofibers.

direction; this nanorod-like morphology might be caused by the fast removal of the PVA. It was also observed that at $700{ }^{\circ} \mathrm{C}$, as a result of high temperature, all nanofibers crushed to form nanoparticles.

The comparison of SEM images in Fig. 2. shows that the calcination at $550{ }^{\circ} \mathrm{C}$ at $1{ }^{\circ} \mathrm{C} / \mathrm{min}$ rate of temperature rise was the best condition for the controlled removal of polymer and ceramic nanofibers and formation of appropriate morphology. The magnification of these ceramic nanofibers and their diameter distribution has been shown in Fig. 3. The average diameter of iron vanadate is $19 \mathrm{~nm}$.

Energy dispersive X-ray spectroscopy (EDX) analysis, which was done along with SEM imaging, was performed on the ceramic nanofibers to determine the elemental composition (Fig. 4). The
EDX pattern confirms the presence of $\mathrm{Fe}, \mathrm{V}$ and $\mathrm{O}$ as the major elements. The other elements must have been created as a result of foil and Au coating residuals.

The vibration modes located at $3250 \mathrm{~cm}^{-1}$ to $3550 \mathrm{~cm}^{-1}$ can be assigned to the asymmetric stretching vibration of $\mathrm{O}-\mathrm{H}$ stretching of residual water. The absorption band at $1620 \mathrm{~cm}^{-1}$ is attributable to $\mathrm{OH}$ vibrations due to water contamination on the surface. The absence of the absorption band of the $\mathrm{C}-\mathrm{H}$ stretching of alkyl groups around $3000 \mathrm{~cm}^{-1}$ demonstrates the complete removal of PVA during calcination [33]. The vibrations at $964,925 \mathrm{~cm}^{-1}$ and $887 \mathrm{~cm}^{-1}$ are due to the terminal stretching of $\mathrm{V}-\mathrm{O}$ and the bridging and $\mathrm{V}-\mathrm{O}-\mathrm{Fe}$ stretching can be observed at 740 and 694. The vibrational mode at $516 \mathrm{~cm}^{-1}$ could be assigned to the $\mathrm{V}-\mathrm{O}-\mathrm{V}$ deformation [34].

$\mathrm{X}$-ray diffraction patterns of the ceramic nanofibers are shown in Fig. 6. Fig. 6a shows the structure of the ceramic compound that was produced by calcination of PVA nanofibers containing iron (III) nitrate: ammonium monovanadate in 1:1 molar proportion. As can be seen in Fig. 6a, $\mathrm{FeVO}_{4}$ was formed in the presence of $\mathrm{Fe}_{2} \mathrm{O}_{3}$. In the next step, changing the iron (III) nitrate:ammonium monovanadate molar proportion to $1: 1.5$ caused the formation of $\mathrm{FeVO}_{4}$. Diffraction peaks at $29.7^{\circ}$, $36.8^{\circ}, 37.6^{\circ}, 50.1^{\circ}, 63.1^{\circ}, 66.1^{\circ}$ and $79.6^{\circ}$ corresponding to (1 $\left.\begin{array}{lll}1 & 0 & 1\end{array}\right),\left(\begin{array}{lll}1 & 1 & 1\end{array}\right),\left(\begin{array}{lll}0 & 0 & 2\end{array}\right),\left(\begin{array}{lll}1 & 1 & 2\end{array}\right)$, $\left(\begin{array}{lll}1 & 0 & 3\end{array}\right),\left(\begin{array}{lll}0 & 3 & 0\end{array}\right)$ and (lll $\left.\begin{array}{lll}1 & 2 & 3\end{array}\right)$ planes are readily recognized in the XRD pattern. The observed diffraction peaks agree well with the rhombohedral structure of iron vanadate (JCPDS Card No. 15-0294). No other phase, except the iron vanadate, was detectable. The calculated lattice parameters of the $\mathrm{FeVO}_{4}$ nanofibers were as follows: space group R$3 \mathrm{a}=5.039 \AA, \mathrm{b}=5.039 \AA, \mathrm{c}=13.77 \AA$ and $\alpha=90.0^{\circ}, \beta=90.0^{\circ}$ and $\gamma=120.0^{\circ}$. Microstructure parameters, such as crystallite size and lattice strain value were obtained using the most commonly applied technique called the uniform deformation model, UDM, of Williamson-Hall (W-H) approach [35].

Because of importance of magnetic properties for practical applications, hysteresis measurements of the nanofibers were performed in an applied 

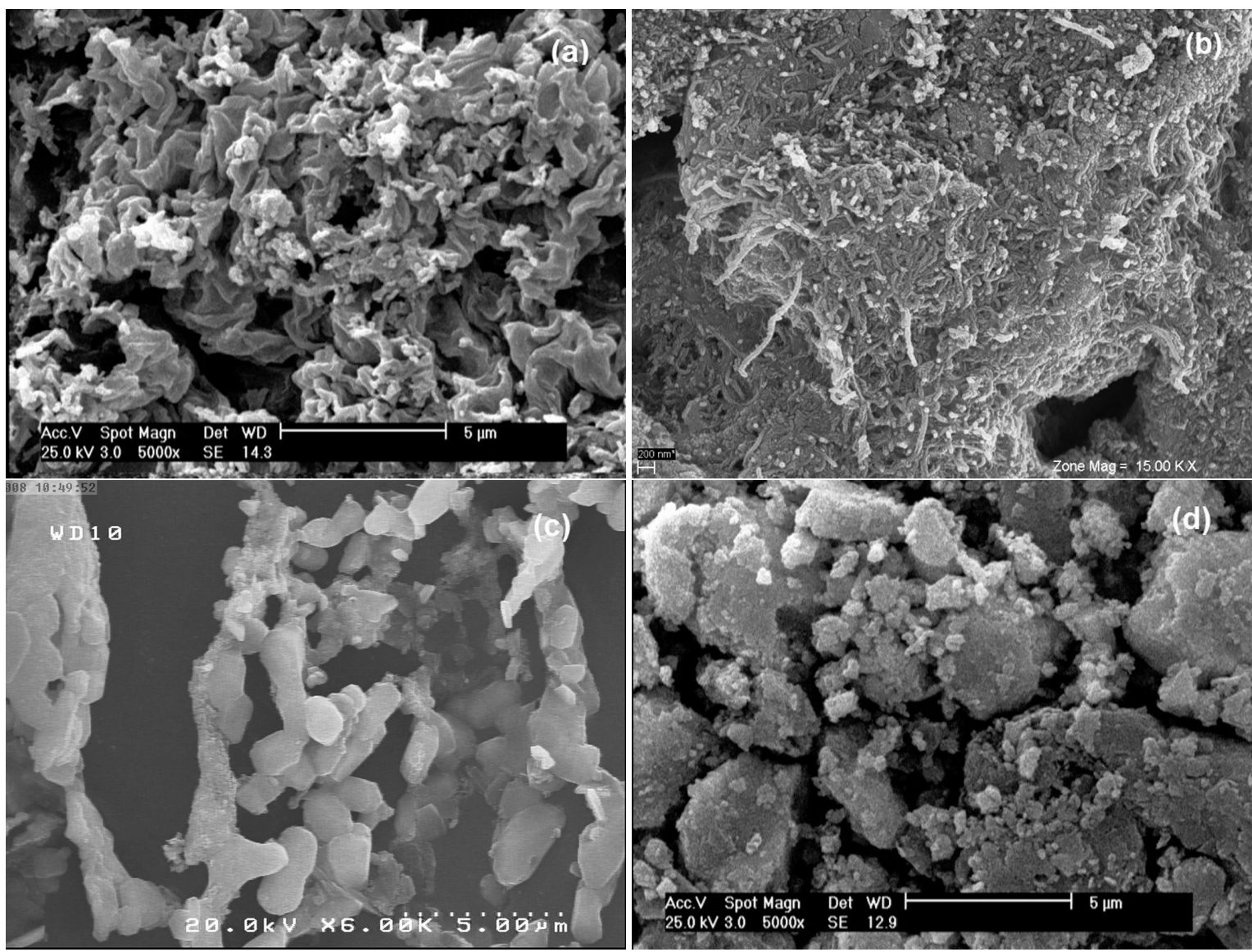

Fig. 2. SEM images of ceramic nanofibers calcined at (a) $500{ }^{\circ} \mathrm{C}, 20^{\circ} \mathrm{C} / \mathrm{min}$ (b) $550{ }^{\circ} \mathrm{C}, 1{ }^{\circ} \mathrm{C} / \mathrm{min}$ (c) $600{ }^{\circ} \mathrm{C}$, $1{ }^{\circ} \mathrm{C} / \min (\mathrm{d}) 700^{\circ} \mathrm{C}, 1^{\circ} \mathrm{C} / \mathrm{min}$ rate of temperature rise.

magnetic field. The magnetic properties were measured at room temperature, with the field sweeping from -15000 Oe to +15000 Oe.

The nanofibers showed high permeability and magnetization (Fig. 7). The saturation magnetization value of iron vanadate was $13 \mathrm{emu} / \mathrm{g}$, whereas, the coercivity values showed a very slight change. The graph shows that new ceramic nanofibers did not aggregate after the removal of the magnetic field.

Brunauer-Emmett-Teller (BET) surface area analysis and Barrett-Joyner-Halenda (BJH) pore size and volume analysis were done on iron vanadate nanofibers. BET analysis enables precise specific surface area evaluation of materials by nitrogen multilayer adsorption measured as a function of relative pressure using a fully automated analyzer. The technique encompasses external area and pore area evaluations to determine the total specific surface area in $\mathrm{m}^{2} / \mathrm{g}$ yielding important information in studying the effects of surface porosity and particle size in many applications. The BJH analysis can also be employed to determine pore area and specific pore volume using adsorption and desorption techniques. This technique characterizes pore size distribution independent of external area due to particle size of the sample. The BET analysis of the iron vanadate nanofibers showed a single point surface area, BET surface area, Langmuir surface area and t-plot external surface area at $\mathrm{p} / \mathrm{p}^{\circ}=0 / 30$ in the amount of $4 / 7294 \mathrm{~m}^{2} / \mathrm{g},-0 / 2735 \mathrm{~m}^{2} / \mathrm{g}$, $-2 / 1346 \mathrm{~m}^{2} / \mathrm{g}$ and $18 / 7931 \mathrm{~m}^{2} / \mathrm{g}$, respectively. Cumulative surface area of pores with the width between $1 / 7000 \mathrm{~nm}$ and 300/0000 nm, obtained from $\mathrm{BJH}$ adsorption, BJH desorption, 

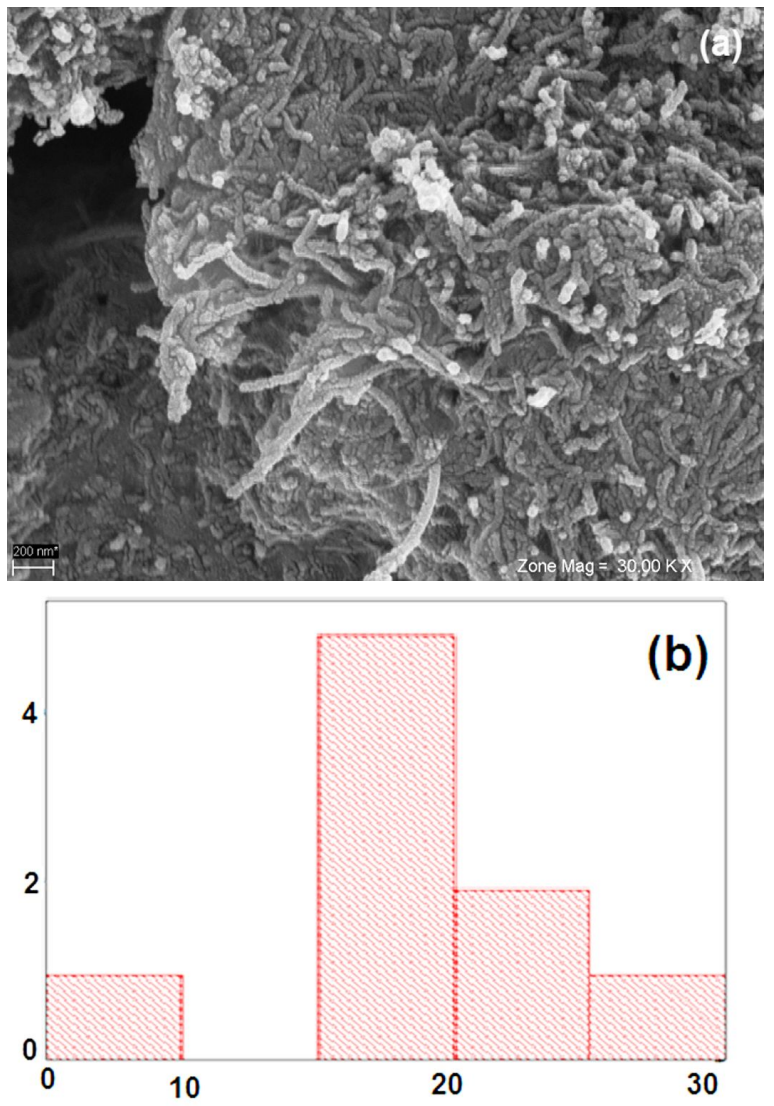

Fig. 3. (a) SEM image (b) fiber diameter distribution of iron vanadate nanofibers.

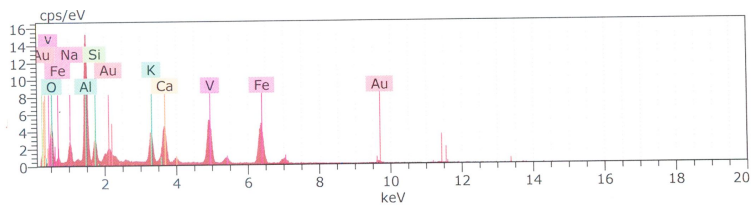

Fig. 4. EDX analysis of iron vanadate nanofibers.

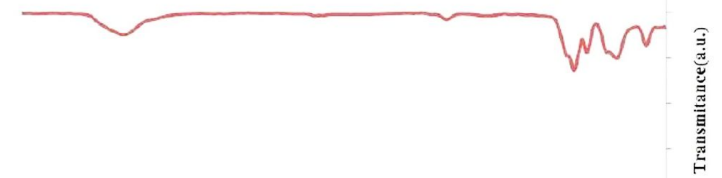

$\begin{array}{llllllllll}4000 & 3600 & 3200 & 2800 & 2400 & 2000 & 1600 & 1200 & 800 & 400\end{array}$

Fig. 5. FT-IR spectrum of iron vanadate nanofibers.

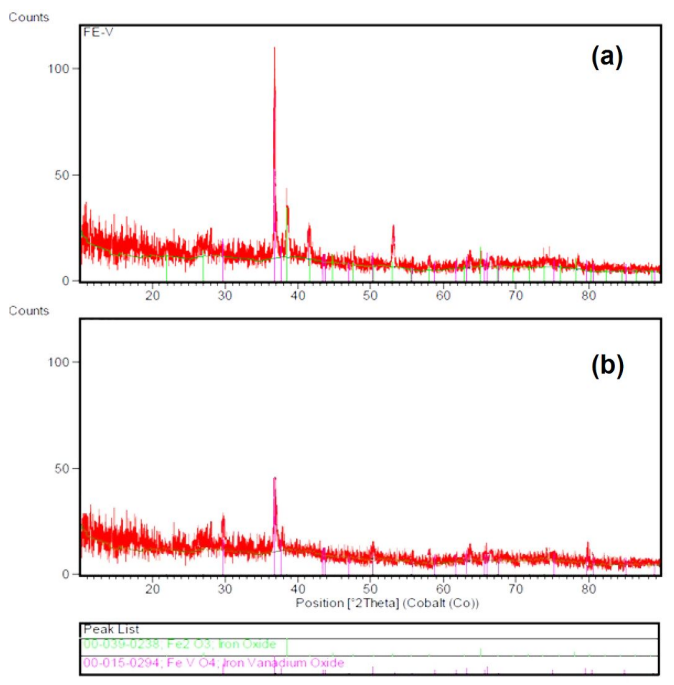

Fig. 6. XRD of ceramic nanofibers produced by calcination of polymeric nanofibers containing iron (III) nitrate: ammonium monovanadate in (a) 1:1, (b) 1:2 molar proportions.

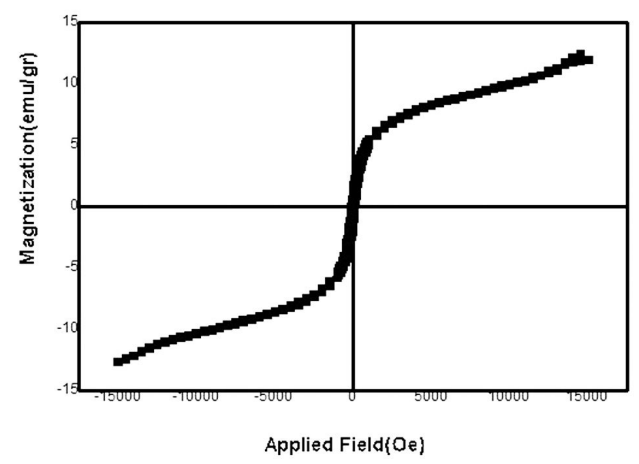

Fig. 7. VSM analysis of iron vanadate nanofibers.

D-H adsorption and D-H desorption was $20.663 \mathrm{~m}^{2} / \mathrm{g}, 19 / 3968 \mathrm{~m}^{2} / \mathrm{g}, 22.092 \mathrm{~m}^{2} / \mathrm{g}$ and $21 / 1445 \mathrm{~m}^{2} / \mathrm{g}$, respectively. Adsorption average pore diameter and desorption average pore diameter calculated by BET were about 412/80269 nm and 405/04713 nm. Single point adsorption and single point desorption total pore volume of pores less than $40 / 3122 \mathrm{~nm}$ width at $\mathrm{p} / \mathrm{p}^{\circ}=0 / 950000000$ obtained from BET were $0 / 028227 \mathrm{~cm}^{3} / \mathrm{g}$ and $0 / 027696 \mathrm{~cm}^{3} / \mathrm{g}$, while BJH adsorption cumulative volume of pores and $\mathrm{BJH}$ desorption 
cumulative volume of pores were $0 / 030120 \mathrm{~cm}^{3} / \mathrm{g}$ and $0 / 030135 \mathrm{~cm}^{3} / \mathrm{g}$. Also t-plot micropore volume was $-0 / 007116 \mathrm{~cm}^{3} / \mathrm{g}$.

\section{Conclusions}

Iron vanadate ceramic nanofibers were fabricated using a combination of electrospinning and sol-gel method for the first time. Morphology of the nanofibers characterized by SEM demonstrated the formation of ceramic iron (III) vanadate as a result of calcination of PVA/iron (III) nitrate/ammonium monovanadate composite nanofibers at $550{ }^{\circ} \mathrm{C}$ with $1{ }^{\circ} \mathrm{C} / \mathrm{min}$ rate of temperature rise. The FT-IR analysis also showed $\mathrm{FeVO}_{4}$ functional group. The presence of $\mathrm{V}, \mathrm{O}$ and $\mathrm{Fe}$ elements was confirmed by EDX analysis. The observed diffraction peaks in $\mathrm{X}$-ray diffraction pattern (XRD) completely agree with the structure of iron vanadate. Surface area, pore size and pore volume of the nanofibers were determined using BET and BJH analyses.

\section{Acknowledgements}

The authors would like to acknowledge the Active Pharmaceutical Ingredients Research Center (APIRC) and the Pharmaceutical Sciences Research Center, Tehran, Medical Science, Islamic Azad University, for equipment and laboratory services.

\section{References}

[1] Lim K., Teck CH., Prog. Polym. Sci., 70 (2017), 1.

[2] Teo W.E., Ramakrishna S., Nanotechnology, 17 (2006), 79.

[3] Patil J.V., Mali S.S., Kamble A.S., Hong CH.K., Kim J.H., PATIL P.S., Appl. Surf. Sci., 423 (2017), 641.

[4] Xue J., Xie J., Liu W., Xia Y., Acc. Chem. Res., 50 (2017), 1976

[5] Thenmozhi S., Dharmaraj N., Kadirvelu K., Yong KIM H., Mater. Sci. Eng. B-Adv., 217 (2017), 36.

[6] Dai Y., Liu W., Formo E., Sun Y., Xia Y., Polym. Advan. Technol., 22 (2011), 326.

[7] ESFAHANi H., Jose R., RAMAKRISHNA S., Materials, 10 (2017), 1238.

[8] LI D., XIA Y., Adv. Mater., 16 (2004), 1151.

[9] Massaglia G., Quaglio M., Mat. Sci. Semicon. Proc., 73 (2018), 13.

[10] Li L., Peng SH., LeE J.K.Y., Ji D., SRinivasan M., RAMAKRISHNA S., Nano Energy, 39 (2017), 111.

[11] Chang Y., Zeng H.CH., Cryst. Growth Des., 4 (2004), 397.

[12] Marberger A., Ferri D., Elsener M., Sagar A., KrÖCHER O., Appl. Catal. B-Environ., 218 (2017), 731.
[13] Sanjeewa L.D., MCMillen C.D., Willett D., Chumanov G., Kolis J.W., J. Solid State Chem., 236 (2016), 61.

[14] Kalai S.R., Gedanken A., Anilkumar P., MANIKANDAN G., KARUNAKARAN C., J. Cluster Sci., 20 (2009), 2991.

[15] Parhi P., Upreti SH., Ramanan A., Cryst. Growth Des., 10 (2010), 5078.

[16] Golmojdeh H., Zanjanch M.A., J. Electron. Mater., 43 (2014), 528.

[17] Palacio L.A., Silva E.R., Catalao R., Silva J.M., Hoyos D.A., Ribeiro F.R., RibEIRO M.F., $J$ Hazard. Mater., 153 (2008), 628.

[18] Reddy CH.V.S., Yeo I.H., Il-Mho S., J. Phys. Chem. Solids, 69 (2008), 1261.

[19] HuAng L., Shi L., ZhaO X., XU J., Li H., Zhang J., ZHANG D., CrystEngComm., 16 (2014), 5128.

[20] Gholamzadeh B.M., Mousavi S.H., RangraZ J.M., J. Mater. Sci-Mater. El., 28 (2017), 1480.

[21] Poizote PH., Lauruelle S., Touboul M., TarasCON J.-M., C.R. Chim., 6 (2003), 125.

[22] Nithya V.D., Selvan R.K., Mater. Res. Bull., 406 (2011), 24

[23] Nithya V.D., Kalai R.S., Sanjeeviraja C., MoHAN R.D., ARUmugam S., Mater. Res. Bull., 46 (2011), 1654.

[24] Kaneti Y.V., LiU M., Zhang X., Bu Y., Yu Y., Sensor. Actuat. B-Chem., 236 (2016), 173.

[25] Heydari A., Sheykhan M., Sadeghi M., RadFAR I., Inorg. Nano-Met. Chem., 47 (2017), 248.

[26] Ma H., Yang X., Tao Z., Liang J., Chen J., CrystEngComm., 13 (2011), 897.

[27] LeE H.S., Mo K.J., OH G.S., Soonim S., Mater. Chem. Phys., 194 (2017), 313.

[28] Luo L., Fei Y., Chen K., Li D., Qia H., J. Alloy. Compd., 649 (2015), 1019.

[29] Lutta S.T., Dong H., Zavaliu P.Y., Whittingham M.S., Mater. Res. Bull., 40 (2005), 383.

[30] Wang F., Zhang H., LiU L., Shin B., Shan F.K., J. Alloy. Compd., 672 (2016), 229.

[31] RENEKER D.H., CHUN I., Nanotechnology, 7 (1996), 216.

[32] Wongsasulak S., Patapeejumruswong M., Weiss J., SUPAPhol P., Yoovidhya T., J. Food Eng., 98 (2010), 370.

[33] CoAtes J., Interpretation of Infrared Spectra. A Practical Approach Encyclopedia of Analytical Chemistry, John Wiley \& Sons Ltd., Chichester, 2000, p. 10815.

[34] Vuk S.A., Orel B., DragiC G., J. Solid State Electr., 5 (2001), 437.

[35] Williamson J.K., Smallman R.E., Philos. Mag., 1 (1956), 34. 